\title{
Adolescent food insecurity in rural Sindh, Pakistan: a cross-sectional survey
}

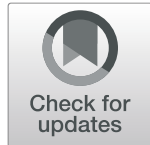

\author{
Sana Sheikh ${ }^{*}$, Romaina lqbal ${ }^{2}$, Rahat Qureshi ${ }^{2}$, Iqbal Azam $^{2}$ and Rubina Barolia ${ }^{3}$
}

\begin{abstract}
Background: Food insecurity (FI) is alarmingly high in developing countries including Pakistan. A quarter of Pakistan's population consists of adolescents yet there is no information on their experience of Fl. Fl at adolescent age have long term effect on mental and physical health hence we aimed to determine the prevalence of food insecurity (FI) among adolescents and compare it with household Fl, and assess social determinants of adolescent Fl.

Methods: A cross-sectional survey on 799 households with unmarried adolescents was conducted from September 2015 to June 2016 in three union councils of Hyderabad, Pakistan. Unmarried 10-19years old girls and boys were interviewed regarding their FI status using Household Food Insecurity Assessment Scale (HFIAS). Household-level FI was also assessed by interviewing mothers of adolescents, and it was compared with adolescent's Fl. Association of adolescent's FI with socio-demographic determinants was explored through Cox regression using STATA version 14.0. and prevalence ratios were estimated.

Results: FI was found among $52.4 \%$ of the adolescents compared to $39 \%$ of the households. Thirty percent of the adolescents were food insecure within the food secure households. Female adolescents were found to be less food insecure (Adjusted Prevalence Ratio (APR) 0.4 95\% Cl [0.3, 0.5]) compared to males. Social determinants like socioeconomic status (SES), crowding index or education of parents were not associated with adolescents' Fl.

Conclusion: Half of the adolescents were found to be food insecure which raises concerns regarding their health in the long run. Gender is an important social determinant of Fl among adolescents which suggests an in-depth exploration of social dynamics of adolescent Fl. We recommend the mixed-methods study to develop contextually relevant interventions to reduce $\mathrm{Fl}$ among this group and improve their health status.
\end{abstract}

Keywords: Adolescents, Food insecurity, Lower-middle-income, Rural, Pakistan

\section{Background}

Every ninth person in the world is suffering from food insecurity (FI) [1]. Food insecurity is defined as a compromise on quantity or quality of food acquisition and consumption due to the lack of resources that hampers normal growth, development, and maintenance of a healthy life [2]. In adolescence, there is an increased demand for nutrients due to growth spurt and to attain puberty [3]. Studies have reported that food insecurity at adolescent stage (10-19

\footnotetext{
* Correspondence: sanasadiasheikh@gmail.com

'Department of Obstetrics and Gynecology, Private wing 2nd floor, Aga Khan University, Stadium road, Karachi 74800, Pakistan

Full list of author information is available at the end of the article
}

years of age) can affect their linear growth [4], high risk of involving in violence perpetration [5] and are twice likely to develop cardiovascular diseases $(2.27 ; 95 \%$ confidence interval [CI], 1.61-3.21) [6].

Pakistan has been categorized among high-risk countries for FI by the Global Food Security Index (GFSI) 2019 [7]. On average $48 \%$ of Pakistan's population is food insecure and with comparatively high FI in rural areas $(60.6 \%$ rural vs. 52.4\% urban) [8]. Current literature on FI from Pakistan and other south Asian countries is focused on women and children under 5 years of age [9-12]. Data on effects of FI on adolescents is scarce globally compared to data on children. A comparative study in United States

(c) The Author(s). 2020 Open Access This article is licensed under a Creative Commons Attribution 4.0 International License, which permits use, sharing, adaptation, distribution and reproduction in any medium or format, as long as you give appropriate credit to the original author(s) and the source, provide a link to the Creative Commons licence, and indicate if changes were made. The images or other third party material in this article are included in the article's Creative Commons licence, unless indicated otherwise in a credit line to the material. If material is not included in the article's Creative Commons licence and your intended use is not permitted by statutory regulation or exceeds the permitted use, you will need to obtain permission directly from the copyright holder. To view a copy of this licence, visit http://creativecommons.org/licenses/by/4.0/ The Creative Commons Public Domain Dedication waiver (http://creativecommons.org/publicdomain/zero/1.0/) applies to the data made available in this article, unless otherwise stated in a credit line to the data. 
(US) found higher odds of mental health impairment among adolescents (OR: 1.33 [95\% CI: 1.05, 1.68]) compared to children (OR: 1.26 [95\% CI: $1.05,1.52]$ ) in severely food insecure households [13]. Another study reported adolescent diet being suffered most due to FI compared to younger age children [14].

Adolescents make 24\% of Pakistan's population but there are no data on FI estimates of adolescents and its socio-demographic factors [15]. Literature reports that $16-17 \%$ adolescents are food insecure in US and Canada $[16,17]$ whereas in developing countries like Ethiopia, Lebanon, and Venezuela $50 \%$ of the adolescents are found food insecure [18-20]. Belchew et al. found the place of residence, lower socio-economic status, dependency ratio, household FI and gender as social determinants of FI among Ethiopian adolescents [18]. Similar factors were also reported from Canada and Brazil [17, 21].

Many studies captured FI among adolescents by indirect response from their caregivers. Globally different studies have determined discordance between reporting of FI by parents and children [19, 22-25]. Consequently aim of this study is to determine the prevalence of food insecurity among adolescent when they are respondent for themselves and compare it with the household FI. It is postulated that during the food crisis adults try to protect the younger ones by cutting down the variety and quantity of their own food and buffer the effect of FI [26, 27]. Hence we expect that adolescents experience less FI compared to their households. FI at the household level and its comparison with adolescent's individual FI has been studied in different settings and found that adolescents may not be protected from FI despite the efforts of the adults in the household [18, 19, 28]. Hence we aim to 1) determine and compare prevalence of FI among adolescents with the household-level FI 2) assess social determinants of FI among adolescents in rural Sindh.

\section{Methods}

A cross-sectional survey was conducted from September 2015 to June 2016 where data was collected over 5 months (October 2015 to February 2016) in three union councils of Hyderabad, Pakistan. Hyderabad is the second largest district in Sindh province. Out of five provinces of Pakistan, the FI situation is worst in Sindh province where FI ranges from 40 to $70 \%$ [29]. Hyderabad has a population of 4.5 million with $40 \%$ rural population. It is further divided into four sub-districts, Hyderabad city, Hyderabad rural, Latifabad, and Qasimabad. We conducted this study in three union councils of sub-district Hyderabad rural namely Masubhurgari, Tando Hyder and Khatyan [30]. The average population of one union council is 30,000 . Common language in the area is Urdu and Sindhi, and $90 \%$ of the residents are Muslims. Less than half of the females (43\%) and $67 \%$ of the males are literate. Predominant occupation is agriculture in this sub-district and in the studied union councils [31].

Households with unmarried adolescents i.e. 10-19 years old girls and boys [32] living in the study area for the past six months participated in the study. Boys and girls with self-reported known co-morbidities which could affect their diet intakes such as chronic renal/cardiac disease, cancers of all types, thalassemia major or other blood disorders and diabetes were excluded. We recruited 799 participants through non-probabilistic sampling (Fig. 1). The research team visited house to house and looked for an eligible adolescent. If any household had more than one eligible participant, then the name of all eligible participants was written on a piece of paper and then the participant was selected through a lucky draw. Study purpose and procedures were explained to the adolescents and their mothers and they were asked for written the ( $<18$ years) or consent as appropriate. Written consent was also taken from parents of participants less than 18 years of age. If the participant was not literate then consent and assent were read out to them by a research team member in the presence of one witness and thumb impression of participant and witness was taken on consent /assent form. Literate participants signed the consent/assent form. No information was collected from the participants who refused the consent. Mothers and adolescents were interviewed separately for FI assessment in privacy to avoid any influence on answers by the presence of the family members.

Data on household-level socio-demographic factors like household assets, age and education of mother and father was collected through a structured questionnaire. Mother was the respondent for socio-demographic factors and a separate written informed consent for household-level data was obtained from her. Information related to FI was collected using the Household Food Insecurity Access Scale (HFIAS). This tool was developed by USAID's Food and Nutrition Technical Assistance (FANTA) group in early 2000 [33] and it has been validated in Pakistan and other LMICs [20,34]. HFIAS has 9 core questions regarding food intake occurring over the last four weeks (30 days). For every question frequency of occurrence is assessed (rarely, sometimes, often). Core questions capture the range of food insecurity from the anxiety of running out of food, compromise on quality or variety of diet, cutting down the portion size and disrupted eating patterns and sleeping hungry. Separate questionnaires were administered to mothers and adolescents for FI assessment. Mothers responded to householdlevel FI. HFIAS questions were rephrased to capture individual-level food insecurity among adolescents. Additional file 1: Adolescent and household questionnaire for FI.

Following the instruction of HFIAS four ordinal categories of food insecurity were developed (food secure, mild insecure, moderate insecure and severe food insecure). The food secure category was assigned when responses to all 


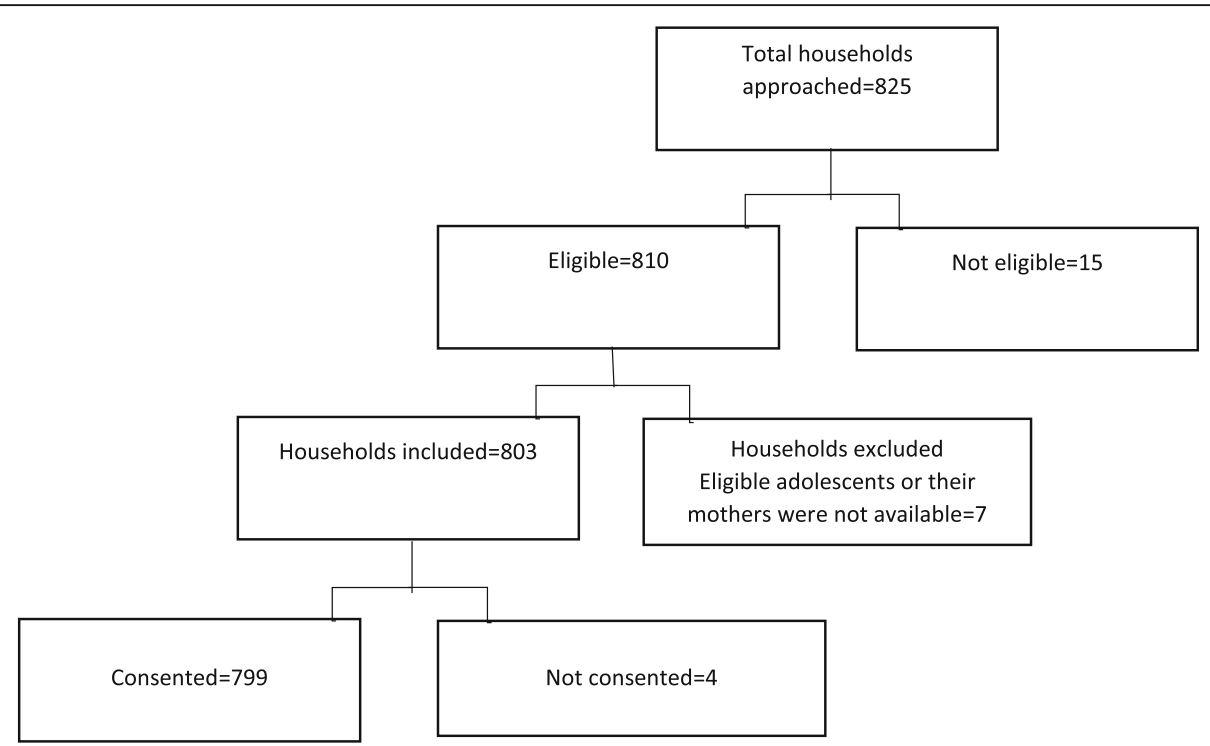

Fig. 1 Participant flow diagram

the nine items were no or anxiety over food was experienced rarely. The mild food insecure category corresponds to worrying sometimes or often for food, and/or eats a limited variety, and/or have undesirable food. Moderate category means a monotonous diet, and/or undesirable food is eaten and portion size is reduced sometimes. Reducing portion size often, and/or skipping meals, and/or going hungry even rarely qualifies for severe food insecurity [33]. All the responses given are scored. A minimum score of zero indicated the most food-secure households/individual, and a maximum score of 27 indicating the most foodinsecure households or individuals. These categories were later collapsed to make a binary variable i.e. food-secure and food-insecure for regression analysis. The foodinsecure category was made by combining mild, moderate and severe food-insecure categories.

Sample size estimation: This study has multiple objectives and the study sample size was calculated for all the objectives. But the sample size for the prevalence of stunting in adolescents came out largest and was used. The sample size was calculated using the WHO sample size calculator keeping prevalence of stunting 47\%, [35] anticipated difference $5 \%$, the sample size of 783 . In this paper, we are focusing on the objective of FI among adolescents. Other objectives will be addressed in future papers.

Statistical analysis: Data was analyzed using Stata version 15.0. For descriptive statistics means \pm standard deviations and proportions were calculated for continuous and categorical variables respectively. Based on descriptive statistics, categories of mother and father education were made. Father education was divided into no education, less than 10 years and more than 10 years of formal education. For mothers, the same education categories were not possible and data distribution depicted only two possible categories i.e. illiterate and literate.

Three categories of SES were developed based on the wealth index. Wealth index was calculated using possession of household items like animal cart, refrigerator, and motorbike, etc. First scores were assigned to household items by estimating the number of individuals having the item and subtracting it from the total sample size. The resulting number was assigned a score of the item. This way the item which was most common got the least score. After this, the score of all items possessed by an individual was summed up and a continuous wealth index was developed. The continuous index was divided into tertiles [36]. To make results interpretable the first tertile was labeled as low socio-economic, second as middle and last as high SES.

Inferential statistics were estimated by univariate analysis applying student's t-test and chi-square and multivariable analysis using Cox regression after checking assumptions. Cox regression is a recommended statistical analysis to estimate prevalence ratios which is an appropriate measure in cross-sectional studies [37]. Crude and adjusted prevalence ratios (APR) were calculated with a 95\% confidence interval. Multivariable analysis was adjusted for the age of the adolescent, sex, number of siblings, mother and father's education and SES. Interactions between household FI and father's education, household FI and mother's education, father's education and SES and father's and mother's education were checked, and none were significant at a $p$-value of 0.20 .

\section{Results}

Altogether, 799 adolescents, were recruited in the study out of which 399 (49.9\%) were males. The mean age of 
adolescents was 13.5 years (SD 2.7 years). About a quarter $(n=217(27.2 \%))$ never attended school and $38.6 \%$ $(n=309)$ has 5 years of schooling. The total number of siblings ranges from zero to 14 with a mean of 5.3 (SD 2.2) siblings per participant. Only $15.5 \%(n=124)$ of mothers had the education of one or more years compared to $53.9 \%$ of the fathers (Table 1 ).

There were $4.6 \%(n=37)$ of the adolescents who reported experiencing severe FI whereas $7.1 \%(n=57)$ of the households were severely food insecure. Half of the adolescents $(47.6 \%,(n=380))$ and $61 \%(n=487)$ of the households were food secure (Fig. 2).

For inferential analysis, 11 cases were excluded because of missing information for socio-demographic variables and data of 788 participants were used. No data were missing for FI status. For regression, the binary variable of food-secure and food-insecure was used. Half of the adolescents were found to be food-insecure (52.6\%) compared to $39 \%$ of the households.

In food secure households, $65.2 \%$ of boys were food insecure compared to $3 \%$ of girls. Food insecure adolescents in food-secure households were $1.2 \pm 0.1$ years younger and fewsmothers were illiterate $(13.4 \%$ vs. $21.4 \%)$ in this group compared to food secure adolescents (Table 2).

Among the adolescents living in food-insecure households, $92 \%$ of the boys and $82 \%$ of the girls were food insecure. Only $8 \%$ of mothers were literate in food insecure group compared to $19 \%$ of literate mothers in food-secure adolescents (Table 3).

Household FI was significantly associated with adolescents' FI and the prevalence of FI among adolescents

Table 1 Baseline characteristics of adolescents

\begin{tabular}{ll}
\hline Variables & $\begin{array}{l}\text { Total } \\
\boldsymbol{n}=799 \\
\mathrm{n}(\%) \\
\text { Mean } \pm \text { SD }\end{array}$ \\
\hline Gender: & $399(49.9)$ \\
Males & $400(51.1)$ \\
Females & $13.5 \pm 2.7$ \\
Age (years) & $3.7 \pm 3.5$ \\
Years of schooling & $5.3 \pm 2.2$ \\
Number of siblings & $2.2 \pm 1.5$ \\
Number of adolescent siblings & $1.2 \pm 1.3$ \\
Male siblings attending school & $0.63 \pm 0.93$ \\
Female siblings attending school & $4.8 \pm 5.15$ \\
Father's years of schooling & $0.96 \pm 2.5$ \\
Mother's years of schooling & \\
Socio-economic status: & $298(37.3)$ \\
Lower & $255(31.9)$ \\
Middle & $246(30.8)$ \\
High &
\end{tabular}

was 2.3 times higher $(95 \%$ CI $1.9,2.9)$ if they belong to a food-insecure household compared to an adolescent who was in the food-secure household. Gender was also a significant contributor to adolescents' FI. FI was $60 \%$ less prevalent if an adolescent was female in comparison to males (APR 0.4 [95\% CI 0.3, 0.5]). Age of adolescents, education status of father or mother, size of the household and SES were not significant factors of adolescents' FI in this study Table 4. None of the interactions were significant. Additional file 1.

\section{Discussion}

We observed that FI is higher among adolescents (52\%) compared to households (39\%), gender is significantly associated with food insecurity of adolescents and it is more prevalent among boys. Household FI is associated with adolescent FI even after adjusting for other sociodemographic factors.

Generally, it is assumed that household-level FI reflects individual FI, but studies have shown that it might not be true $[22,23]$. We also found FI among $68 \%$ of the adolescent living in food-secure households. This emphasizes that the measurement of household-level FI may not be a true reflection of adolescents FI and should be measured separately. Adolescents are at an age where they can sense the stress in the house and try to play their part in buffering the effects of FI [25]. Literature reports that adolescents voluntarily cut-down their portion size during food shortages which at times go unnoticed by adults of the family [38]. Frongillo explained a few reasons for parents' lack of information regarding adolescent FI through their qualitative work. The author wrote that when parents reduce their portion sizes, do not discuss the FI situation of households with their children, they assume that they have protected the children from hunger and anxiety of FI [25]. Hence, adolescents' FI is under-reported by adults of the household. However, adolescents take cue from the change in household meals or expenditure pattern and are aware of FI in household. They give up their share of food or generate resources to improve the FI situation [25, 39, 40].

While assessing the social determinants of adolescent's FI study found household FI to be an independent determinant. The same has been reported in studies conducted in Ethiopia (Adjusted odds ratio $(\mathrm{AOR})=2.86, P<0.001$ ) [18]. It can happen when households experience FI for a longer duration then adults cannot buffer its effects and young members are exposed to FI [18]. Our study was for a short duration and cannot differentiate between acute and chronic FI among participants. Other than household FI, none of the variables at the household level are associated with adolescent FI in this study. The number of siblings served as the proxy indicator for household size in the study and it has no association with adolescent FI. This study's finding is consistent with existing literature 


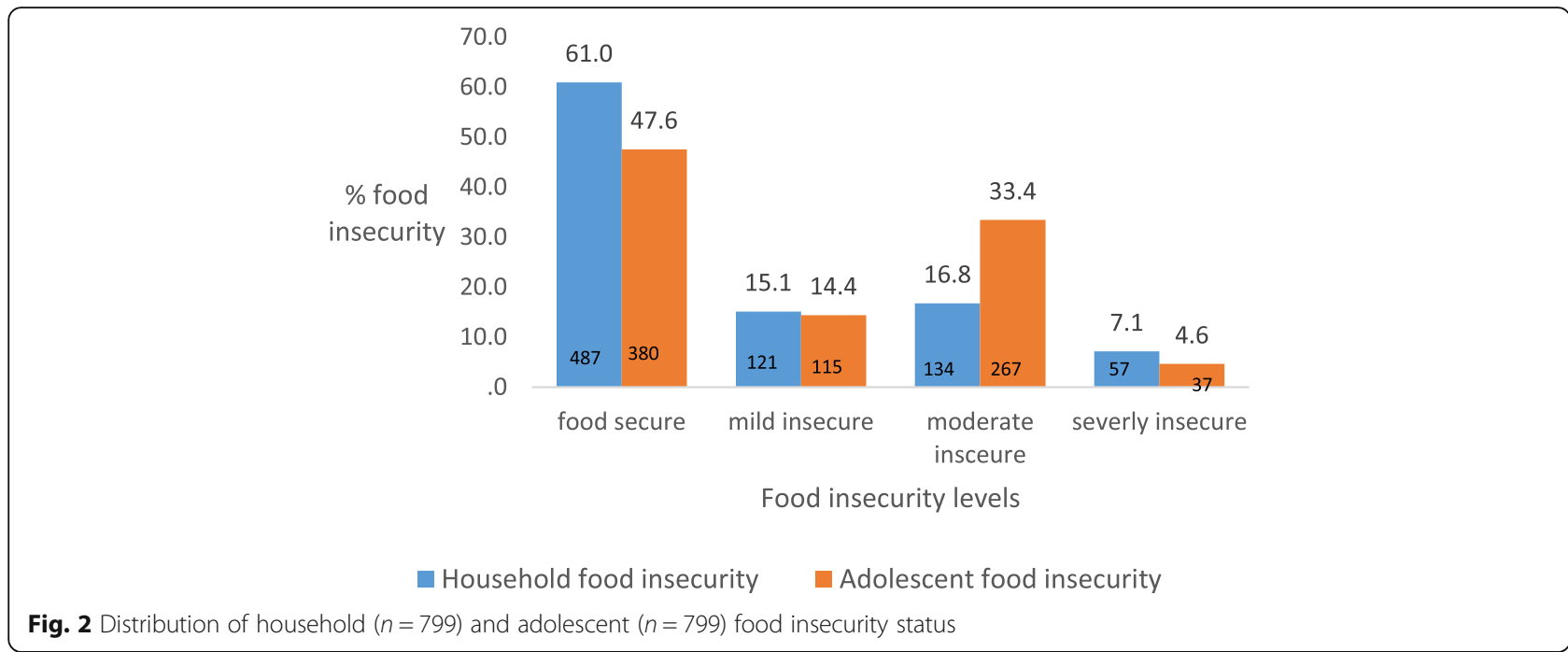

where household size is not a significant factor of adolescent's FI $[18,26]$. We did not find an association between SES of households and FI for rural adolescents. SES has been documented as a significant factor of FI by other studies (low-income households, AOR $=1.61, P<0.026$ ) $[17,18]$. However, literature has inconsistent findings on the effect of household income on FI. Our findings support the perception that poverty is not responsible alone for FI rather requires a multilevel exploration of other determinants. These determinants include community neighborhood (access to food retail store), social support, tobacco or substance use by family members, food price fluctuations, unexpected events like medical or other expenses, etc. [41].

In our study FI is found more among boys compared to girls. The same pattern was reported from Bangladesh where it was observed that in food insecure household men were more likely to consume less food [42]. Belchew et al. reported biased food distribution within the household among male and female adolescents in Ethiopia resulting in high FI (AOR 1.46, 95\% CI 1.12, 1.92) among girls [43]. A systematic review stated mixed

Table 2 Comparison of characteristics of food secure and insecure adolescents in food-secure households

\begin{tabular}{|c|c|c|c|}
\hline Variables & $\begin{array}{l}\text { Food secure adolescents } \\
\boldsymbol{N}=337 \\
\mathrm{~N}(\%) \\
\text { Mean } \pm \text { SD }\end{array}$ & $\begin{array}{l}\text { Food insecure adolescents } \\
\boldsymbol{N}=142 \\
\mathrm{~N}(\%) \\
\text { Mean } \pm \text { SD }\end{array}$ & $\boldsymbol{P}$-value \\
\hline Age of the adolescent & $14.0 \pm 2.7$ & $13.2 \pm 2.8$ & $<0.01$ \\
\hline \multicolumn{4}{|l|}{ Father's years of schooling } \\
\hline No schooling & $143(42.4)$ & $54(38.0)$ & \multirow[t]{3}{*}{0.21} \\
\hline$<10$ years & $70(20.8)$ & $40(28.2)$ & \\
\hline$\geq 10$ years & $124(36.8)$ & $48(33.8)$ & \\
\hline \multicolumn{4}{|l|}{ Mother's years of schooling } \\
\hline Illiterate & $265(78.6)$ & $123(86.6)$ & \multirow[t]{2}{*}{0.04} \\
\hline Literate & $72(21.4)$ & 19 (13.4) & \\
\hline \multicolumn{4}{|l|}{ Wealth tertiles } \\
\hline Low & $77(22.8)$ & $42(29.6)$ & \multirow[t]{3}{*}{0.29} \\
\hline Middle & $101(30.0)$ & $40(28.2)$ & \\
\hline high & $159(47.2)$ & $60(42.3)$ & \\
\hline Total number of siblings & $5.1 \pm 2.3$ & $5.3 \pm 2.1$ & 0.43 \\
\hline \multicolumn{3}{|l|}{ Gender } & \multirow[t]{3}{*}{$<0.01$} \\
\hline Male & $72(21.4)$ & $132(93.0)$ & \\
\hline Female & $265(78.6)$ & $10(7.0)$ & \\
\hline
\end{tabular}


Table 3 Comparison of characteristics of food secure and insecure adolescents in food-insecure households

\begin{tabular}{|c|c|c|c|}
\hline Variables & $\begin{array}{l}\text { Food secure adolescents } \\
\boldsymbol{N}=36 \\
\mathrm{~N}(\%) \\
\text { Mean } \pm \text { SD }\end{array}$ & $\begin{array}{l}\text { Food insecure adolescents } \\
\boldsymbol{N}=273 \\
\mathrm{~N}(\%) \\
\text { Mean } \pm \text { SD }\end{array}$ & $\boldsymbol{P}$-value \\
\hline Age of the adolescent & $13.5 \pm 2.5$ & $13.1 \pm 2.4$ & 0.37 \\
\hline \multicolumn{4}{|l|}{ Father's years of schooling } \\
\hline No schooling & $21(58.3)$ & $143(52.4)$ & \multirow[t]{3}{*}{0.62} \\
\hline$<10$ years & $6(16.7)$ & $65(23.8)$ & \\
\hline$\geq 10$ years & $9(25.0)$ & $65(23.8)$ & \\
\hline \multicolumn{4}{|l|}{ Mother's years of schooling } \\
\hline Illiterate & $29(80.6)$ & $250(91.6)$ & \multirow[t]{2}{*}{0.03} \\
\hline Literate & $7(19.4)$ & $23(8.4)$ & \\
\hline \multicolumn{4}{|l|}{ Wealth tertiles } \\
\hline Low & $13(36.1)$ & $133(48.7)$ & \multirow[t]{3}{*}{0.11} \\
\hline Middle & $16(44.4)$ & $106(38.8)$ & \\
\hline high & $7(19.4)$ & $34(12.5)$ & \\
\hline Total number of siblings & $5.2 \pm 2.2$ & $5.6 \pm 2.3$ & 0.37 \\
\hline \multicolumn{4}{|l|}{ Gender } \\
\hline Male & $14(38.9)$ & $179(65.6)$ & \multirow[t]{2}{*}{$<0.01$} \\
\hline Female & $22(61.1)$ & $94(34.4)$ & \\
\hline
\end{tabular}

Chi-square test was used to compare the characteristics

Table 4 Factors associated with food insecurity among adolescents

\begin{tabular}{|c|c|c|c|c|}
\hline Variables & $\begin{array}{l}\text { Total adolescents } \\
\boldsymbol{N}=788 \\
\mathrm{n}(\%) \\
\text { Mean } \pm \text { SD }\end{array}$ & $\begin{array}{l}\text { Food insecure adolescents } \\
\boldsymbol{N}=415 \\
\mathrm{n}(\%) \\
\text { Mean } \pm \text { SD }\end{array}$ & $\begin{array}{l}\text { Crude Prevalence Ratio } \\
(95 \% \mathrm{Cl})\end{array}$ & $\begin{array}{l}\text { Adjusted Prevalence Ratio } \\
(95 \% \mathrm{Cl})\end{array}$ \\
\hline \multicolumn{5}{|l|}{ Food secure household } \\
\hline Food insecure & $479(60.7)$ & $142(34.3)$ & 1 & 1 \\
\hline household & 309 (39.2) & $273(65.7)$ & $2.9(2.4,3.6)$ & $2.3(1.9,2.9)$ \\
\hline Male & $397(50.3)$ & $311(74.9)$ & 1 & 1 \\
\hline Female & 391 (49.6) & $104(25.1)$ & $0.3(0.2,0.4)$ & $0.4(0.3,0.5)$ \\
\hline Age of adolescent & $13.54 \pm 2.71$ & $13.15 \pm 2.60$ & $0.94(0.91,0.98)$ & $0.9(0.9,1.0)$ \\
\hline \multicolumn{5}{|l|}{ Father's years of schooling } \\
\hline No schooling & $361(45.8)$ & $197(47.4)$ & 1 & 1 \\
\hline$<10$ years & $181(23.0)$ & $105(25.3)$ & $1.0(0.8,1.3)$ & $1.1(0.8,1.4)$ \\
\hline$\geq 10$ years & $246(31.2)$ & $113(27.2)$ & $0.8(0.6,1.0)$ & $1.0(0.8,1.3)$ \\
\hline \multicolumn{5}{|l|}{ Mother's years of schooling } \\
\hline Illiterate & $667(84.6)$ & $373(89.8)$ & 1 & 1 \\
\hline Literate & $121(15.4)$ & $42(10.1)$ & $0.6(0.4,0.8)$ & $0.8(0.6,1.2)$ \\
\hline Total number of siblings & $5.35 \pm 2.29$ & $0 \pm 5.51$ & $1.0(0.9,1.0)$ & $1.0(0.9,1.0)$ \\
\hline \multicolumn{5}{|l|}{ Socio-economic status: } \\
\hline Low & $296(37.6)$ & $188(45.3)$ & $1.8(1.4,2.3)$ & $1.1(0.8,1.5)$ \\
\hline Middle & $251(31.8)$ & $143(34.4)$ & $1.6(1.2,2.1)$ & $1.1(0.8,1.5)$ \\
\hline High & $241(30.5)$ & $84(20.2)$ & 1 & 1 \\
\hline
\end{tabular}


results for the role of gender on intra-household food allocation in South Asia [44]. National Nutrition Survey (NNS) 2011 of Pakistan captured mothers' responses on gender discrimination in food distribution among children and found no discrimination by them [8]. The inconsistent results reflect the complexity of the FI phenomenon and a need to explore what is being perceived by FI. Understanding of food deprivation is shaped by culture and societal norms and can be contextually driven. Because of patriarchal society females in South Asia are habitual to demand less food than their body requirement [45] . This could have affected the reporting of FI amongst young females for themselves.

We also observed that girls' response to FI was less discordant to household FI compared to boys ( $8 \%$ for girls vs. $37 \%$ for boys). The higher concordance of FI response between households and females has also been observed in Burkina Faso among adult women. Nanama et al. found that households with multiple wives, the youngest wife experience similar FI as of the household. Authors posited that this occurs because of the less autonomy and higher dependency of young wives on their households that tie the increase and decrease of their FI with that of the households compared to older wives [46]. We anticipate that patriarchal culture in Pakistan allows male adolescents to bargain for better food and express their voice if they are not being provided with the food of their choice regardless of the situation of the household FI. Hence, their FI can be different from household FI. Whereas, females are more conditioned to accept and go along with the household situation and hence have similar FI experience as that of the household.

The strengths of our study include rural communitybased data of adolescents and the estimation of their FI by responses from themselves and it has an adequate sample size to answer the multiple research questions. The literature on adolescent FI is relatively scarce from south Asia and this study is a contribution to the existing literature on adolescent FI from this part of the world.

It was a cross-sectional survey hence causality of sociodemographic factors with adolescents' FI cannot be established. However, it is advisable to conduct a survey first if baseline data is not available on the study topic, so the design of the study was justified. One limitation of the study was the non-availability of data on the employment status of adolescents and water sanitation and hygiene (WASH) indicators. Both of these factors are important for the effective absorption of the nutrients and can affect individual-level FI. In our opinion, findings of our study may have not been affected as the purpose was to elicit the information on acquisition of food and issue of absorption of nutrients comes later. Another limitation is nonprobability sampling which can limit the generalizability of the results. But the communities we studied are homogenous socially, culturally and have a similar lifestyle. Hence we think results are generalizable to the communities with similar contexts. We did not account for the clustering effect hence it is advised to interpret statistical significance with caution. Though with a few numbers of clusters it is unlikely that clustering affects the estimates [47].

\section{Conclusion}

We found that FI is prevalent among adolescents, more in boys than girls and half of the adolescents are food insecure. This warrants immediate attention by the government as the measurement of FI at the household level may mask FI at the individual level; especially in the adolescent age group. We feel that an in-depth investigation of the socio-cultural dynamics of FI is needed. We recommend mixed-methods studies to unpack the complexities around this phenomenon and then design contextually relevant interventions to reduce FI among this group and improve their health status.

\section{Supplementary information}

Supplementary information accompanies this paper at https://doi.org/10. 1186/s40795-020-00343-W.

\section{Additional file 1.}

\section{Abbreviations}

APR: Adjusted prevalence ratio; AOR: Adjusted odds ratio; Cl: confidence interval; FI: Food insecurity; HFIAS: Household Food Insecurity Access Scale; LMIC: Lower-middle-income countries; NNS: National Nutrition Survey; OR: Odds ratio; SD: Standard deviation; SES: Socioeconomic status; WASH: Water, sanitation, and hygiene

\section{Acknowledgments}

We thank our data collection team for their untiring efforts and our participants to make this study possible. Special thanks to Farrukh Raza for his field site supervision and support.

\section{Authors' contributions}

SS has full access to all study data and takes responsibility for the study integrity and the accuracy of data analysis. SS (Principal Investigator) conceived and designed the study and obtained funding, analyzed data and drafted the manuscript. Rl supervised the study and provided technical input at the study design and manuscript writing stage. RQ supported study field activities and $\mathrm{RQ}$ and RB interpreted the findings. IA supervised the statistical analysis and write up of the findings. All authors read and approved the final manuscript.

\section{Funding}

This work was supported by SEED grant Aga Khan University grant number PF70/0315. Funder has no role in the designing, execution, analysis of the study or in the interpretation of study findings.

\section{Availability of data and materials}

The datasets used and/or analyzed during the current study are available from the corresponding author on reasonable request.

\section{Ethics approval and consent to participate}

Written assent (for participants $<18$ years of age) and consent (for participants $>18$ years of age and parents of adolescents) were obtained from all the participants. Ethical approval was obtained from the ethical review committee of Aga Khan University (3960-Obs-ERC-15). 


\section{Consent for publication}

Not applicable.

\section{Competing interests}

The authors declare that they have no competing interests.

\section{Author details}

'Department of Obstetrics and Gynecology, Private wing 2nd floor, Aga Khan University, Stadium road, Karachi 74800, Pakistan. ${ }^{2}$ Department of Community Health Sciences, Ibn-e-Ridwan building, Aga Khan University, Stadium road, Karachi 74800, Pakistan. ${ }^{3}$ School of Nursing and Midwifery, Aga Khan University, Stadium road, Karachi 74800, Pakistan.

\section{Received: 10 October 2019 Accepted: 11 March 2020}

\section{Published online: 26 March 2020}

\section{References}

1. Current $\mathrm{WHO}$ recommendations for adolescent anthropometry: WHO; [Available from: http://www.unsystem.org/SCN/archives/adolescents/ch04. htm]. Accessed 18 July 2014

2. Food security in the US: Measurement: United States Department of Agriculture Economic Research Service; 2014 [27 November 2018]. Available from: https://www.ers.usda.gov/topics/food-nutrition-assistance/foodsecurity-in-the-us/measurement.aspx\#.U5nWcoWJuDk. Accessed $27 \mathrm{Nov}$ 2018.

3. Das JK, Lassi ZS, Hoodbhoy Z, et al. Nutrition for the next generation: olde children and adolescents. Ann Nutr Metab. 2018;72(3):56-64.

4. Belachew T, Lindstrom D, Hadley C, et al. Food insecurity and linear growth of adolescents in Jimma Zone, Southwest Ethiopia. Nutr J. 2013:12(1):55.

5. Karmaliani R, Mcfarlane J, Somani R, et al. Peer violence perpetration and victimization: prevalence, associated factors and pathways among 1752 sixth grade boys and girls in schools in Pakistan. PLoS One. 2017;12(8): e0180833.

6. Shanafelt A, Hearst MO, Wang Q, et al. Food insecurity and rural adolescent personal health, home, and academic environments. J Sch Health. 2016; 86(6):472-80.

7. Global Food Security Index: The Economist, Intelligence unit; 2019. Available from: https://foodsecurityindex.eiu.com/Index. Accessed 4 Nov 2019.

8. Bhutta Z, Soofi S, Zaidi S, et al. National nutrition survey Pakistan 2011 Karachi: Aga Khan University, Pakistan; 2011.

9. Aurino E, Morrow V. "Food prices were high, and the dal became watery". Mixed-method evidence on household food insecurity and children's diets in India. World Dev. 2018;111:211-24.

10. Khan MA, Shah SAA. Food insecurity in Pakistan: causes and policy response. J Agric Environ Ethics. 2011:24(5):493-509.

11. Sreeramareddy CT, Ramakrishnareddy N, Subramaniam M. Association between household food access insecurity and nutritional status indicators among children aged< 5 years in Nepal: results from a national, crosssectional household survey. Public Health Nutr. 2015;18(16):2906-14.

12. Mascie-Taylor C, Marks M, Goto R, et al. Impact of a cash-for-work programme on food consumption and nutrition among women and children facing food insecurity in rural Bangladesh. Bull World Health Organ. 2010:88:854-60

13. Burke MP, Martini LH, Cayır E, et al. Severity of household food insecurity is positively associated with mental disorders among children and adolescents in the United States. J Nutr. 2016;146(10):2019-26.

14. Eicher-Miller HA, Zhao Y. Evidence for the age-specific relationship of food insecurity and key dietary outcomes among US children and adolescents. Nutr Res Rev. 2018;31(1):98-113.

15. Farrell $P$, Thow AM, Abimbola $S$, et al. How food insecurity could lead to obesity in LMICs: when not enough is too much: a realist review of how food insecurity could lead to obesity in low-and middle-income countries. Health Promot Int. 2018;33(5):812-26.

16. Klosek K. Food insecurity among teens: John Hopkins University, Zanvyl Krieger School of Arts \& Sciences, Baltimore, US.; 2019. Available from: https://govex.jhu.edu/wiki/food-insecurity-among-teens/. Accessed 1 Apr 2019.

17. Tarasuk V, Mitchell A, Dachner N. Household food insecurity in Canada, 2014. Toronto: Research to identify policy options to reduce food insecurity (PROOF); 2014.
18. Belachew T, Lindstrom D, Gebremariam A, et al. Predictors of chronic food insecurity among adolescents in Southwest Ethiopia: a longitudinal study. BMC Public Health. 2012;12(1):604.

19. Bernal J, Frongillo EA, Rivera JA. Food insecurity reported by children, but not by mothers, is associated with lower quality of diet and shifts in foods consumed. Matern Child Nutr. 2016;12(3):546-57.

20. Jomaa L, Naja F, Kharroubi S, et al. Prevalence and correlates of food insecurity among Lebanese households with children aged 4-18 years: findings from a national cross-sectional study. Public Health Nutr. 2019;22(2):202-11.

21. de Souza Bittencourt L, dos Santos SMC, de Jesus Pinto E, et al. Factors associated with food insecurity in households of public school students of Salvador City, Bahia, Brazil. J Health Popul Nutr. 2013;31(4):471.

22. Carlos Chavez Fiorella L, Hernandez DC, Harris GJ, Grzywacz JG. Household food security discordance among Latino adolescents and parents. Am J Health Behav. 2017:41(6):775-83.

23. Nord M, Hanson K. Adult caregiver reports of adolescents' food security do not agree well with adolescents' own reports. J Hunger Environ Nutr. 2012; 7(4):363-80

24. Kuku O, Gundersen C, Garasky S. Differences in food insecurity between adults and children in Zimbabwe. Food Policy. 2011;36(2):311-7.

25. Frongillo EA, Fram MS, Escobar-Alegría JL, et al. Concordance and discordance of the knowledge, understanding, and description of Children's experience of food insecurity among Hispanic adults and children. Fam Commun Health. 2019;42(4):237-44.

26. Hadley C, Lindstrom D, Tessema F, et al. Gender bias in the food insecurity experience of Ethiopian adolescents. Soc Sci Med. 2008;66(2):427-38.

27. Leonard WR. Household-level strategies for protecting children from seasonal food scarcity. Soc Sci Med. 1991;33(10):1127-33.

28. Fram MS, Frongillo EA, Draper $\mathrm{CL}$, et al. Development and validation of a child report assessment of child food insecurity and comparison to parent report assessment. J Hunger Environ Nutr. 2013;8(2):128-45.

29. Report On The Status Of Millennium Development Goals Sindh. United Nations Development Programme Pakistan \& Government of Sindh; 2012.

30. Hyderabad District, Sindh. 2014. [Available from: http://en.wikipedia.org/ wiki/Hyderabad_District,_Sindh. Accessed 27 Mar 2014

31. Sheikh S, Qureshi RN, Khowaja AR, et al. Health care provider knowledge and routine management of pre-eclampsia in Pakistan. Reprod Health. 2016; 13(2):104.

32. Adolescent health: World Health Organization; 2018. Available from: http:// www.who.int/topics/adolescent health/en/. Accessed 22 June 2018.

33. Jennifer C, Swindale A, Bilinsky P. Household Food Insecurity Access Scale (HFIAS) for Measurement of Household Food Access: Indicator Guide (v. 3). Washington, D.C: Food and Nutrition Technical Assistance Project, Academy for Educational Development; 2007.

34. Psaki S, Bhutta ZA, Ahmed T, et al. Household food access and child malnutrition: results from the eight-country MAL-ED study. Popul Health Metrics. 2012:10(1):24.

35. Rahman A, Karim R. Prevalence of stunting and thinness among adolescents in rural area of Bangladesh. J Asian Sci Res. 2014:4(1):39-46.

36. Howe LD, Hargreaves JR, Huttly SR. Issues in the construction of wealth indices for the measurement of socio-economic position in low-income countries. Emerg Themes Epidemiol. 2008;5(1):3.

37. Coutinho L, Scazufca M, Menezes PR. Methods for estimating prevalence ratios in cross-sectional studies. Revista de saude publica. 2008;42(6):992-8.

38. Fatmaningrum D, Roshita A, Februhartanty J. Coping strategies for food insecurity among adolescent girls during the lean season in East Nusa Tenggara, Indonesia: a qualitative study. Br J Nutr. 2016;116(S1):S42-S8.

39. Bernal J, Frongillo EA, Herrera $\mathrm{H}$, et al. Children live, feel, and respond to experiences of food insecurity that compromise their development and weight status in peri-urban Venezuela. J Nutr. 2012;142(7):1343-9.

40. Fram MS, Frongillo EA, Jones SJ, et al. Children are aware of food insecurity and take responsibility for managing food resources. J Nutr. 2011;141(6): 1114-9.

41. Olabiyi OM, Mclntyre L. Determinants of food insecurity in higher-income households in Canada. J Hunger Environ Nutr. 2014;9(4):433-48.

42. Naved R. Intrahousehold impact of the transfer of modern agricultural technology: a gender perspective. Washington, DC: International Food Policy Research Institute; 2000. FCND Discussion Paper.

43. Belachew T, Hadley C, Lindstrom D, et al. Gender differences in food insecurity and morbidity among adolescents in Southwest Ethiopia. Pediatrics. 2011;127(2):e398-405. 
44. Harris-Fry H, Shrestha N, Costello A, et al. Determinants of intra-household food allocation between adults in South Asia-a systematic review. Int J Equity Health. 2017;16(1):107.

45. Messer E. Intra-household allocation of food and health care: Current findings and understandings-introduction. Soc Sci Med. 1997;44(11):1675-84.

46. Nanama S, Frongillo EA. Women's rank modifies the relationship between household and women's food insecurity in complex households in northern Burkina Faso. Food Policy. 2012;37(3):217-25.

47. Cameron AC, Miller DL. A practitioner's guide to cluster-robust inference. J Hum Resour. 2015;50(2):317-72.

\section{Publisher's Note}

Springer Nature remains neutral with regard to jurisdictional claims in published maps and institutional affiliations.

Ready to submit your research? Choose BMC and benefit from:

- fast, convenient online submission

- thorough peer review by experienced researchers in your field

- rapid publication on acceptance

- support for research data, including large and complex data types

- gold Open Access which fosters wider collaboration and increased citations

- maximum visibility for your research: over $100 \mathrm{M}$ website views per year

At BMC, research is always in progress.

Learn more biomedcentral.com/submissions 